\title{
Epidemiology and Characteristics of Chronic Daily Headaches in Children
}

\author{
Irfan Nagouri $^{1}$ · Dhan Raj Bagri ${ }^{1}$ [1 . J. N. Sharma ${ }^{1}$
}

Received: 12 June 2021 / Accepted: 1 September 2021/Published online: 5 October 2021

c) Dr. K C Chaudhuri Foundation 2021

To the Editor: Chronic daily headaches ( $\mathrm{CDH})$ is defined by the International Classification of Headache Disorders 3rd edition (ICHD-3) based on adult research. Pediatric issues including age-/gender-wise prevalence, characteristics, and effects of normal developmental continuum have less been studied [1]. This hospital-based, observational, descriptive study done at a tertiary care center over a period of one year included 240 children $(\mathrm{M}: \mathrm{F}=1: 1.7)$ aged 5-15 y attending the OPD with CDH. Disability due to headache was assessed using the Ped MIDAS scoring system [2] and severity using the Visual Analog Scale (VAS) for children $>6 y$ and Faces Pain Scale (FPS) for $<6$ y [3, 4]. SPSS-22 was used for data analysis. Chronic tension type headache (CTTH - 53\%) and chronic migraine (CM - 37\%) were most common types with female predominance. Sixty-seven percent patients had bilateral headache. Sixty-three percent had steady pain and 37\% had throbbing headache. Seventy percent children had moderate and $25 \%$ had severe headache. Precipitating factor was stress in $66 \%$ cases of CTTH and $48 \%$ cases of CM; sleep deprivation in $11 \%$ patients of CTTH and $35 \%$ patients of $\mathrm{CM}$, and bright light in $5.26 \%$ cases of CTTH and $15 \%$ cases of CM. Excessive use of electronic devices was associated with presence of headache in adolescents $(>10 \mathrm{y})(p<0.05)$. Relieving factors were analgesics in $49 \%$ patients of CTTH and $38 \%$ patients of $\mathrm{CM}$, and dark and quiet environment in $13.3 \%$ cases of CTTH and $25 \%$ cases CM. Associated symptom was nausea in $8 \%$ of patients with CTTH and $55 \%$ patients with $\mathrm{CM}$; vomiting in $3 \%$ of patients with $\mathrm{CTTH}$ and $14 \%$ of patients with CM (60\% males) and photophobia in $31.8 \%$ of patients with CM. CM without aura (33\%) was more common than migraine with aura (3\%). Family history was positive in $13.63 \%$. Mean Ped MIDAS score was 20; $72.63 \%$ had mild, $33 \%$ had moderate, and $5 \%$ children had little or no disability.

\section{Declarations}

Conflict of Interest None.

\section{References}

1. Headache Classification Committee of the International Headache Society (IHS). The international classification of headache disorders, 3rd edition. Cephalalgia. 2018;38:1-211.

2. Hershey AD, Powers SW, Vockell AL, LeCates S, Kabbouche MA, Maynard MK. PedMIDAS: development of a questionnaire to assess disability of migraines in children. Neurology. 2001;11:2034-9.

3. Wewers ME, Lowe NK. A critical review of visual analogue scales in the measurement of clinical phenomena. Res Nurs Health. 1990;13:227-36.

4. Tsze DS, von Baeyer CL, Bulloch B, Dayan PS. Validation of self-report pain scales in children. Pediatrics. 2013;132:e971-9.

Publisher's Note Springer Nature remains neutral with regard to jurisdictional claims in published maps and institutional affiliations.

Dhan Raj Bagri

meena.drdhanraj6@gmail.com

1 Sir Padampat Institute of Neonatology \& Pediatric Health (SPINPH), J. K. Lon Hospital SMS Medical College, Jaipur, Rajasthan 302004, India 